\title{
Thermodynamic Analysis and Purification for Source Materials in Sublimation Crystal Growth of Aluminum Nitride
}

\author{
Li. $\mathrm{Du}^{1}$ and J.H. Edgar ${ }^{1}$ \\ ${ }^{1}$ Department of Chemical Engineering, Kansas State University \\ Manhattan, KS 66506-5102, U.S.A.
}

\begin{abstract}
Source material purification according to a thermodynamic analysis is reported for the sublimation crystal growth of aluminum nitride in an inert reactor. $\mathrm{OAlOH}$ is strongly favored over all other possible oxygen containing compounds in both the Al-O-H-N and Al-O-H-C-N systems, while $\mathrm{Al}_{2} \mathrm{O}$ the most favorable oxygen containing gas species for Al-O-N system, become secondary favorable gas species. A low temperature $\left(<1200{ }^{\circ} \mathrm{C}\right)$ treatment is effective in eliminating oxygen and hydrogen from the source powder. Carbon monoxide is another important oxygen containing gas species in the Al-O-H-C-N system, and is favored over $\mathrm{Al}_{2} \mathrm{O}$ at certain temperature and pressure. Carbothermal reduction with intentionally added carbon (graphite) can further reduce the oxygen concentration. Experiments show that high-temperature sintering minimizes the oxygen concentration and reduces the specific surface area of the source. With $5.5 \%$ of mass loss, source purification reduced impurities concentrations to $0.019 \pm 0.001 \mathrm{wt} \% \mathrm{O}, 7 \pm 1 \mathrm{ppmH}$, and $0.010 \pm 0.004 \mathrm{wt} \% \mathrm{C}$.
\end{abstract}

\section{INTRODUCTION}

Single crystal aluminum nitride is an important substrate for UV-LEDs and laser diodes (LDs): its high thermal conductivity helps to dissipate heat generated by devices and its small lattice mismatch makes it well-suited for $\mathrm{Al}_{\mathrm{x}} \mathrm{Ga}_{1-\mathrm{x}} \mathrm{N}$ epitaxy. However, these properties are affected by the impurities in the AlN, specifically oxygen incorporation causes Al vacancies that degrade its thermal conductivity and can reduce its lattice constants [1].

In moist or dry air aluminum compounds form hydroxides and/or oxides [2]. Li et al. reported that amorphous $\mathrm{AlOOH}$ is produced in moist air at room temperature and can be further hydrolyzed to form mixtures of $\mathrm{Al}(\mathrm{OH})_{3}$ [3]. The surface oxide or hydroxide may be a mixture of $\mathrm{Al}_{2} \mathrm{O}_{3} / \mathrm{Al}(\mathrm{OH})_{3} / \mathrm{AlOOH}[4]$. Our previous study summarized the analysis by several groups on AlN hydroxides [5], and experimentally demonstrated that a heat treatment under $900^{\circ} \mathrm{C}$ in either vacuum or under nitrogen can decompose the aluminum hydroxides, removing oxygen via the formation of water. Carbon is another common impurity in the AlN. It can be beneficial: Fukuyama's group [6-7] showed that carbon can reduce oxide to nitride.

This study applies thermodynamic analysis to AlN crystal sublimation and recondensation growth process to predict the most stable species present, and experimentally tests source purification by annealing and sintering experiments. High temperature $\left(>1900^{\circ} \mathrm{C}\right)$ source sintering with or without low temperature $\left(<1200^{\circ} \mathrm{C}\right)$ annealing process are discussed and compared. The benefit of adding carbon to reduce the oxygen concentration was investigated theoretically and experimentally. 


\section{THEORY CALCULATION}

The thermodynamics calculations were based on a non-reacting reactor (tungsten furnace). In the Al-O-H-N system, oxygen and hydrogen were assumed to be the main impurities, originating from the AlN source powder ( $0.9 \mathrm{wt} \%$ oxygen, $0.024 \mathrm{wt} \%$ hydrogen). In the Al-O-H-C-N system, carbon could be considered a residual impurity in the as-received powder $(0.06 \mathrm{wt} \%)$ or an impurity intentionally added to facilitate oxygen removal. Pure $\mathrm{N}_{2}$ gas was the ambient gas. The total pressure was calculated from the ideal gas law knowing the initial temperature and pressure. Two solid-vapor equilibriums were assumed, one at the source sublimation zone, the other at the crystal growth zone. The crystal growth zone was assumed to be 5 to $50{ }^{\circ} \mathrm{C}$ lower in temperature than the source sublimation zone.

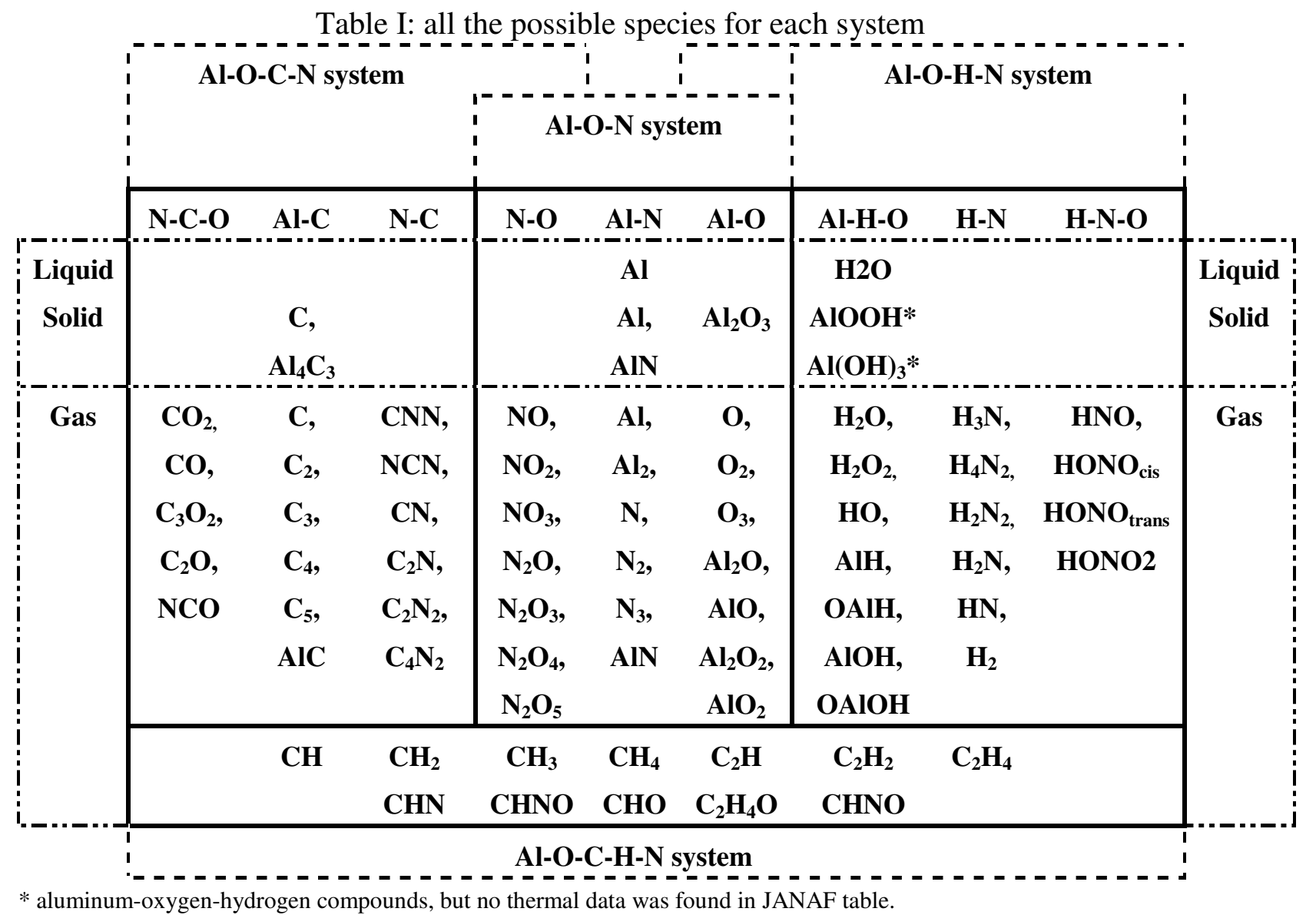

All the possible species according to the JANAF table [8] are presented in Table I.

Reactions used in thermodynamic calculation can be represented as:

$$
a A(s)+b B(g)=c C(g)+D d(g)
$$

Then the equilibrium constant of the reaction can be expressed by:

$$
K=\frac{\alpha_{C}^{c} \cdot \alpha_{D}^{d}}{\alpha_{A}^{a} \cdot \alpha_{B}^{b}}=\exp \left(-\frac{\Delta r G^{0}}{R T}\right)=\exp \left(-\frac{\sum v_{i} \Delta_{f} G_{i}{ }^{0}}{R T}\right)
$$

Where $\alpha_{\mathrm{i}}$ is the activity of the reactants or products $\mathrm{i}$ with reference to their standard states (pure substance, activities of unity and $0.1 \mathrm{M} \mathrm{Pa}$ ) and $v$ is the stoichiometric coefficients. Free energy of formation $\Delta_{\mathrm{f}} \mathrm{G}^{0}{ }_{\mathrm{i}}$ comes from JANAF data [8]. 


\section{$\underline{\text { Al-O-N system }}$}

Our previous study [9] showed that $\mathrm{Al}_{2} \mathrm{O}$ was the most favorable oxygen containing gas species in the Al-O-N system. The reaction $\mathrm{Al}_{2} \mathrm{O}_{3}(\mathrm{~s})+4 \mathrm{Al}(\mathrm{g})=3 \mathrm{Al}_{2} \mathrm{O}$ has a positive $\mathrm{LogKs}$; all the reactions forming other oxygen containing species have negative LogKs. Both $\mathrm{Al}$ and $\mathrm{O}$ begin to enter the gas phase at $1900^{\circ} \mathrm{C}$. Much of the oxygen originally present in the source enters the gas phase: $56.3 \%$ at $2200^{\circ} \mathrm{C}$ and $99.5 \%$ at $2300^{\circ} \mathrm{C}$. In comparison, less of the $\mathrm{Al}$ present in the source enters the gas phase: $6.0 \%$ at $2200^{\circ} \mathrm{C}$ and $17.1 \%$ at $2300^{\circ} \mathrm{C}$. The stability of $\mathrm{Al}_{2} \mathrm{O}$ at high temperature suggests that high temperature $\left(>1900^{\circ} \mathrm{C}\right)$ sintering of $\mathrm{AlN}$ source can remove the oxygen from the solid phase.
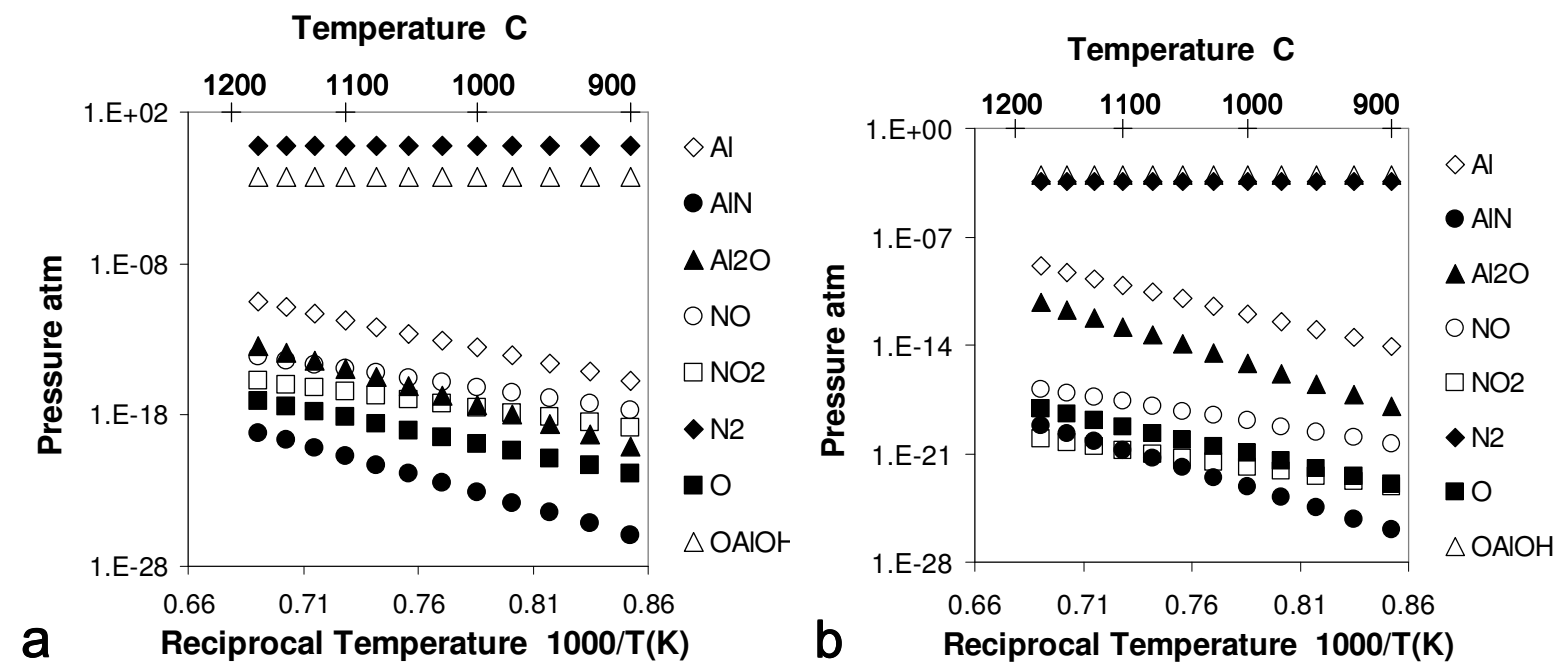

Figure 1: Partial pressure of the selected gas species in Al-O-H-N system; a, total pressure is 500 torr $(0.658 \mathrm{~atm})$; $\mathrm{b}$, total pressure is 1 torr $(0.001 \mathrm{~atm})$.

\section{Al-O-H-N system}

Aluminum hydroxides are easily decomposed in the AlN source annealing process. For a total pressure of 500 torr (0.658 atm, Fig1a) and 1 torr (0.001 atm, high vacuum, Fig.1b), thermodynamics calculation predict that between $900{ }^{\circ} \mathrm{C}$ to $1200{ }^{\circ} \mathrm{C}$, the major gas-phase species present are $\mathrm{N}_{2}$ and $\mathrm{OAlOH}$. Although the $\mathrm{Al}$ vapor higher pressure is higher under vacuum (about $10^{-9}$ ), it is a minor gas species. Gas species $\mathrm{Al}_{2} \mathrm{O}, \mathrm{Al}_{2}, \mathrm{AlO}, \mathrm{AlN}, \mathrm{Al}_{2} \mathrm{O}_{2}, \mathrm{AlO}_{2}$, $\mathrm{NO}, \mathrm{NO}_{2}, \mathrm{~N}_{2} \mathrm{O}, \mathrm{N}_{3}, \mathrm{O}, \mathrm{O}_{2}$ with pressure lower than $10^{-10}$ atm are negligible, while other gas species $\mathrm{NO}_{3}, \mathrm{~N}_{2} \mathrm{O}_{3}, \mathrm{~N}_{2} \mathrm{O}_{4}, \mathrm{~N}_{2} \mathrm{O}_{5}, \mathrm{O}_{3}, \mathrm{~N}, \mathrm{H}_{2} \mathrm{O}, \mathrm{H}_{2} \mathrm{O}_{2}, \mathrm{HO}, \mathrm{H}_{2}, \mathrm{AlH}, \mathrm{OAlH}, \mathrm{AlOH}, \mathrm{H}_{3} \mathrm{~N}_{2} \mathrm{H}_{4} \mathrm{H}_{2}$, $\mathrm{H}_{2} \mathrm{H}_{2}, \mathrm{H}_{2} \mathrm{~N}, \mathrm{HN}, \mathrm{HNO}, \mathrm{HONOc}, \mathrm{HONOt}, \mathrm{HONO}_{2}$, with pressure lower than $10^{-28}$ atm are unlikely to be present in the vapor. While $\mathrm{Al}_{2} \mathrm{O}$ gas is only stable at high temperature (higher than $1900^{\circ} \mathrm{C}$ ), $\mathrm{OAlOH}$ gas is stable at lower temperature regardless of the ambient. In addition, the lower $\mathrm{Al} / \mathrm{O}$ mole ratio in $\mathrm{OAlOH}(0.5)$ than $\mathrm{Al}_{2} \mathrm{O}$ (2) indicates less source mass is lost during the removal of oxygen from the solid phase.

\section{Al-O-C-H-N system}

For the system with carbon, thermodynamic analysis shows that the major gas-phase species present are still $\mathrm{N}_{2}$ and $\mathrm{OAlOH}$ (with pressure of about $10^{-3}$ ). Consider carbon as a residual impurity in the as-received powder; figure $2 \mathrm{a}$ represents the partial pressure for the 
gas species that has partial pressure higher than $10^{-13}$ at the calculated temperature range. Between $900{ }^{\circ} \mathrm{C}$ to $1200{ }^{\circ} \mathrm{C}, \mathrm{CO}$ is a minor gas species (with a partial pressure between $10^{-6}$ $-10^{-8}$ ). The addition of carbon does not change the concentrations of those species which are negligibly small in the Al-O-H-N system. Carbon containing species $\mathrm{C}_{2} \mathrm{~N}_{2}, \mathrm{C}_{2} \mathrm{~N}, \mathrm{C}_{4} \mathrm{~N}_{2}, \mathrm{CNN}$, $\mathrm{NCN}, \mathrm{C}, \mathrm{C}_{2}, \mathrm{C}_{3}, \mathrm{C}_{4}, \mathrm{C}_{5}, \mathrm{C}_{3} \mathrm{O}_{2}, \mathrm{C}_{2} \mathrm{O}, \mathrm{AlC}, \mathrm{NCO}, \mathrm{CH}, \mathrm{CH}_{2}, \mathrm{CH}_{3}, \mathrm{CH}_{4}, \mathrm{C}_{2} \mathrm{H}, \mathrm{C}_{2} \mathrm{H}_{2}, \mathrm{C}_{2} \mathrm{H}_{4}, \mathrm{CHN}$, $\mathrm{CHNO}, \mathrm{CHO}, \mathrm{C}_{2} \mathrm{H}_{4} \mathrm{O}$ and $\mathrm{CHNO}$ with pressure lower than $10^{-12}$ atm are also negligible. Between $1400{ }^{\circ} \mathrm{C}$ to $1600{ }^{\circ} \mathrm{C}$ (Fig. 2a), CO gas with pressure between $10^{-4}-10^{-6}$ become the third most major gas species. Between $1900{ }^{\circ} \mathrm{C}$ to $2100{ }^{\circ} \mathrm{C}$ (Fig.2a), both the $\mathrm{Al}$ and $\mathrm{Al}_{2} \mathrm{O}$ partial pressures increased faster than that of $\mathrm{CO}$ gas as the temperature increased. The $\mathrm{Al}_{2} \mathrm{O}$ partial pressure finally exceeds $\mathrm{CO}$ above $2050{ }^{\circ} \mathrm{C}$. Since the partial pressure of cyanogen $(\mathrm{CN})$ is lower than $10^{-10}$ at 1400 to $1600{ }^{\circ} \mathrm{C}$ and $10^{-8}$ at 1900 to $2100{ }^{\circ} \mathrm{C}, \mathrm{CO}$ is the main carbon containing gas species in Al-O-C-H-N system in an inert reactor.

Aluminum oxides and hydroxide can be written as $\left(\mathrm{Al}_{2} \mathrm{O}_{3}\right)_{\mathrm{x}}\left(\mathrm{H}_{2} \mathrm{O}\right)_{\mathrm{y}}$ to emphasize the water they contain. By adding carbon, oxygen can be removed by transferring all the oxygen from $\mathrm{Al}_{2} \mathrm{O}_{3}$ to $\mathrm{CO}$, thus the total moles of carbon are the same as that of oxygen in $\mathrm{Al}_{2} \mathrm{O}_{3}$. Then partial pressures for this new system were represented in Fig.2b. Compare Fig.2a and Fig.2b, $\mathrm{N}_{2}$ and $\mathrm{OAlOH}$ are still the major gas species at all the calculated temperature range $\left(900{ }^{\circ} \mathrm{C}\right.$ to $2100{ }^{\circ} \mathrm{C}$ ) for the system with added carbon (fig.2b). $\mathrm{CO}$ is become the third major gas and has significant pressure increasing since $1400{ }^{\circ} \mathrm{C}$. At the same temperature, the partial pressure of $\mathrm{CO}$ is higher for the system with added carbon (fig.2b). The pressure of cyanogen is lower than $10^{-10}$ in this temperature range. Between $1900{ }^{\circ} \mathrm{C}$ to $2100{ }^{\circ} \mathrm{C}$, the sharp increasing in the $\mathrm{Al}_{2} \mathrm{O}$ partial pressure was constrained by additional $\mathrm{CO}$, and was always lower than that of $\mathrm{CO}$.
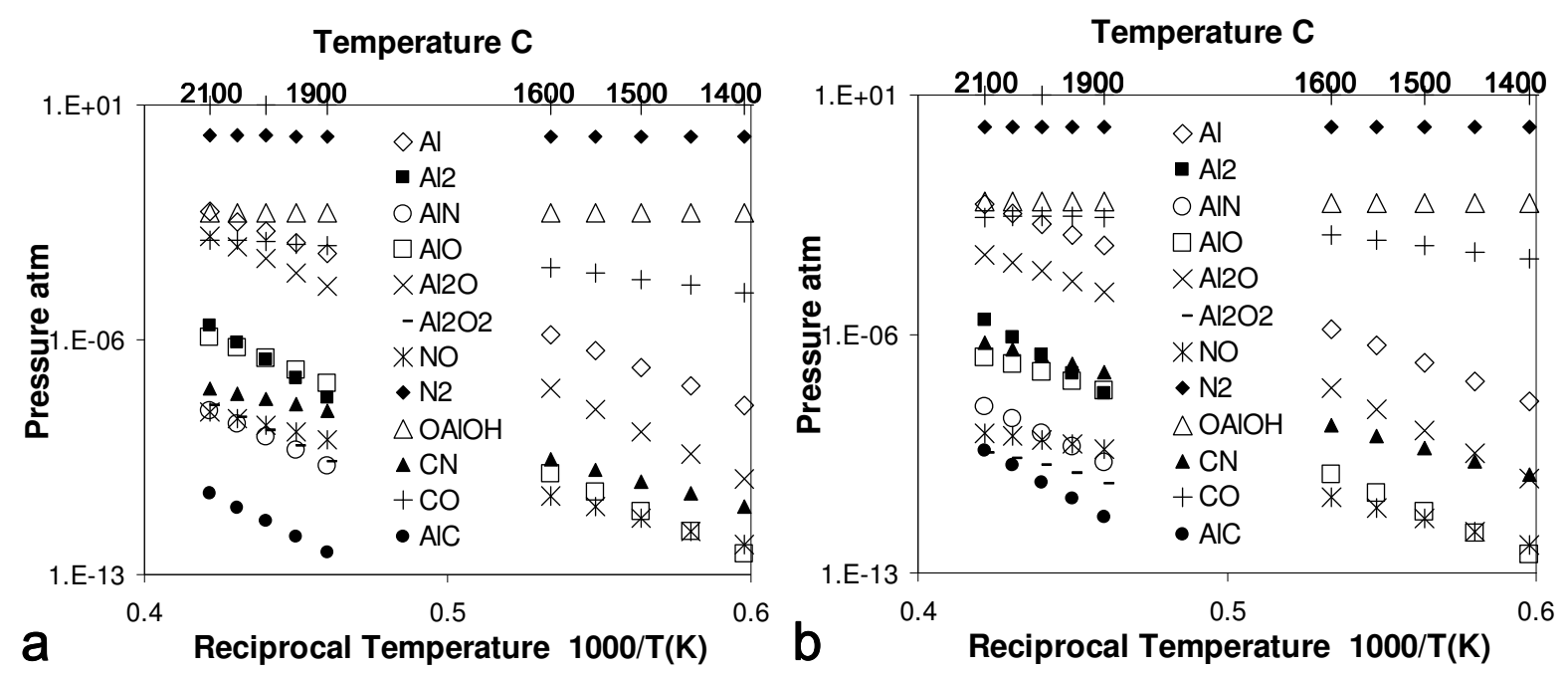

Figure 2: Partial pressure of the selected gas species in Al-O-C-H-N system for as received AlN source (a) and AlN source with additional carbon (b)

\section{EXPERIMENT}

A resistively-heated tungsten furnace with a vertical temperature gradient of about $5{ }^{\circ} \mathrm{C}$ $/ \mathrm{cm}$ was used in the experiments. The AIN source powders were placed in a tungsten crucible (25 mm diameter) within a tungsten retort. Three sets of experiments were run to remove 
oxygen from the AlN source. In the first set of experiments, the AlN powder was sintered at about $1950{ }^{\circ} \mathrm{C}$ in 615 torr of nitrogen for 2, 5 and 10 hours. In the second set of experiments, the AlN was first annealed at $960-1000{ }^{\circ} \mathrm{C}$ for 2 to 10 hours in a vacuum, and then sintered at about $1920{ }^{\circ} \mathrm{C}, 615$ torr of $\mathrm{N}_{2}$ for 2 to10 h; the high temperature sintering time was the same as the low temperature annealing time. In the third set of experiments, carbon was added, in the same amount as the oxygen present in $\left(\mathrm{Al}_{2} \mathrm{O}_{3}\right)_{\mathrm{x}}$ minus the carbon moles initially present in the source. A carbothermal reduction at about $1500^{\circ} \mathrm{C}$ and 1050 torr followed the low temperature annealing (at about $1000{ }^{\circ} \mathrm{C}$ in vacuum). Then the source was sintered at $1920^{\circ} \mathrm{C}$, and 615 torr $\mathrm{N}_{2}$ ), the time range for each step was 2 hours. The mass of the source was measured before and after the experiments to determine the percentage of source mass lost. The oxygen, carbon and hydrogen concentrations after the heat treatment were measured by inert gas fusion technique (LECO analysis).
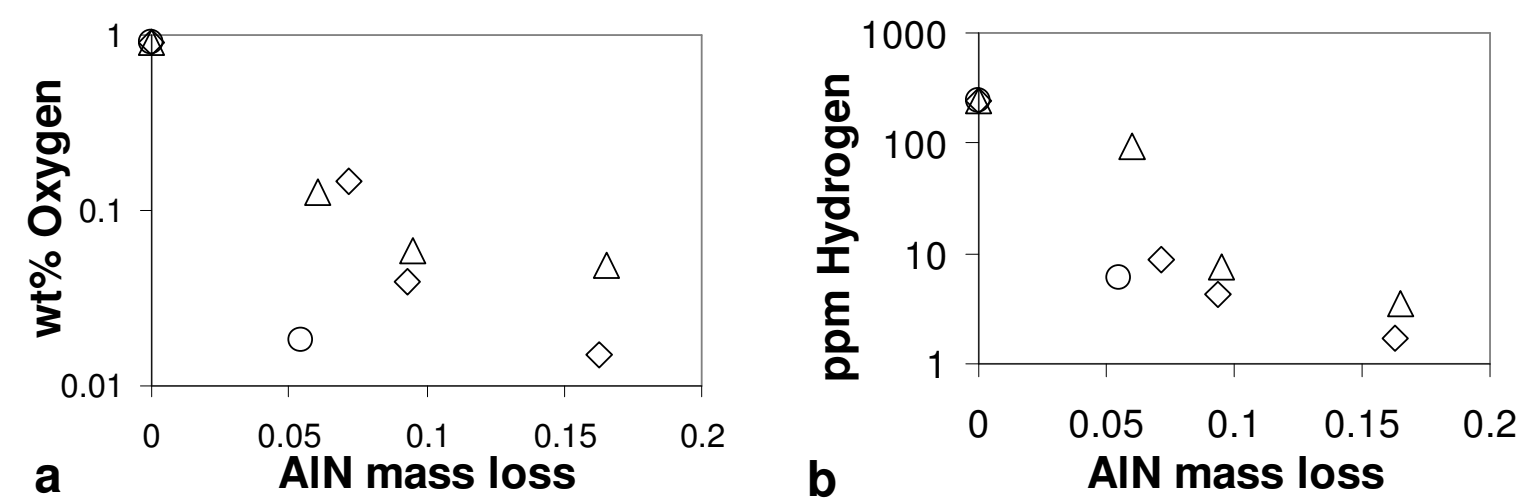

Figure 3: Oxygen (a) and hydrogen (b) concentration in the AlN source as function of the source mass loss. Symbols: triangle - source only sintering at $1950^{\circ} \mathrm{C}$; diamond - source annealing at $960-1000{ }^{\circ} \mathrm{C}$ followed by sintering at $1920^{\circ} \mathrm{C}$; circle - source with added carbon for carbothermal reduction during the annealing process.

\section{DISCUSSION}

Due to the temperature gradient in the furnace, the source powder lost mass due to sublimation. We previously proved that reducing the surface area of the AlN source through particle agglomeration and an increase in their average size is effective at reducing the oxygen concentration [5]. The particle size significantly increased after high temperature sintering $\left(>1900{ }^{\circ} \mathrm{C}\right)$, however long time sintering at this temperature results in high source mass loss.

According to thermodynamic analysis, $\mathrm{OAlOH}, \mathrm{CO}$, and $\mathrm{Al}_{2} \mathrm{O}$ are the major impurity containing species when the AlN source is directly heated to a temperature higher than 1900 ${ }^{\circ} \mathrm{C}$. Their significantly higher partial pressure than $\mathrm{Al}$ and stability in the vapor helps remove impurities from the solid phase. In contrast, $\mathrm{OAlOH}$ is the only impurity containing species if first annealing AlN source at about $1000{ }^{\circ} \mathrm{C}$. The oxygen and hydrogen can be removed first through $\mathrm{OAlOH}$ volatilization and then by $\mathrm{Al}_{2} \mathrm{O}$ forming when the temperature is increased 
to $1920^{\circ} \mathrm{C}$. The low $\mathrm{Al} / \mathrm{O}$ ratio of $\mathrm{OAlOH}$ over $\mathrm{Al}_{2} \mathrm{O}$ indicates the source purification with low AlN source mass loss.

Figure 3 shows the $\mathrm{O}$ (a) and $\mathrm{H}$ (b) concentration in the AlN source vesus source mass loss. Comparing the two sets of experiments (triangle stands for the source only sintering at $1950^{\circ} \mathrm{C}$; diamond stands for the source annealing at $960-1000{ }^{\circ} \mathrm{C}$ followed by sintering at $1920^{\circ} \mathrm{C}$ ), for the same AlN source mass loss, the experiments with the low temperature annealing step have lower $\mathrm{O}$ and $\mathrm{H}$ concentration in general, indicating more effective source purification.

Thermodynamic analysis predicts that $\mathrm{CO}$ is the major oxygen containing species and only carbon containing vapor species between $1400{ }^{\circ} \mathrm{C}$ to $1600{ }^{\circ} \mathrm{C}$, thus a carbothermal reduction at $1500^{\circ} \mathrm{C}$ after the $1000^{\circ} \mathrm{C}$ annealing can further reduce oxygen with nearly zero source mass loss. Considering that as-received AlN powder has an impurity concentration of $0.9 \mathrm{wt} \% \mathrm{O}, 0.024 \mathrm{wt} \% \mathrm{H}$, and $0.06 \mathrm{wt} \% \mathrm{C}$, the atomic ratio of $\mathrm{C}: \mathrm{H}: \mathrm{O}$ is $4: 19: 45$. Since aluminum oxides and hydroxides can be written in the form of $\left(\mathrm{Al}_{2} \mathrm{O}_{3}\right)_{x}\left(\mathrm{H}_{2} \mathrm{O}\right)_{y}$, additional $\mathrm{C}$ is need to remove oxygen from the aluminum oxide while minimizing the mass source loss. After high temperature sintering, $\mathrm{O}$ and $\mathrm{H}$ concentration were tested (the circle in fig.3). With only $5.5 \%$ of mass loss, the purification produced a source with low $\mathrm{O}, \mathrm{H}$, and $\mathrm{C}$ concentrations of $0.018 \mathrm{wt} \%, 6 \mathrm{ppm}$, and $0.006 \mathrm{wt} \%$.

However, the theoretical calculation may only refer to the oxygen and hydrogen that originates from surface aluminum oxides and hydroxides. If the impurities were trapped inside of the materials (or volume impurities), for example, the impurities dissolved in the bulk AlN or trapped at internal surfaces of voids, the impurity diffusion kinetics need take into consideration. Therefore there is a minimum impurity concentration that sintering can achieve, which has been addressed before [5] in our study from different point of view. Meanwhile, the stability of the major impurity containing species $\mathrm{OAlOH}, \mathrm{CO}$, and $\mathrm{Al}_{2} \mathrm{O}$ in the gas phase suggest that impurities trapped inside of the materials (or volume impurities) may be removed by recrystallization of aluminum nitride by, for example, completely subliming and recondensing the source material.

\section{CONCLUSIONS}

A two step process (a low temperature $\left(<1000^{\circ} \mathrm{C}\right)$ annealing plus a high temperature $\left(>1900^{\circ} \mathrm{C}\right)$ sintering) was shown theoretically and experimentally to be effective in reducing the oxygen in a AlN source for AlN sublimation crystal growth. High-temperature sintering minimizes the oxygen concentration by reducing the specific surface area of the source and transferring oxygen to the vapor phase as $\mathrm{Al}_{2} \mathrm{O}$. Low temperature annealing removes aluminum hydroxide with a low source mass loss compared to high temperature sintering. Intentionally adding carbon can further reduce the oxygen concentration and reduce the source total treatment time. Carbothermal reduction at a low temperature (around $1500^{\circ} \mathrm{C}$ ) can reach the minimum AlN mass loss possible. With only $5.5 \%$ of mass loss, the purification produced a source with low $\mathrm{O}, \mathrm{H}$, and $\mathrm{C}$ concentrations of $0.019 \pm 0.001 \mathrm{wt} \% \mathrm{O}, 7 \pm 1 \mathrm{ppm} \mathrm{H}$, and $0.010 \pm 0.004 \mathrm{wt} \% \mathrm{C}$. 


\section{ACKNOWLEDGMENTS}

Support for this project from the II-VI Foundation is greatly appreciated.

\section{REFERENCES}

1. M. Miyanaga, N. Mizuhara, S. Fujiwara, M. Shimazu, H. Nakahata, T. Kawase, J. Crystal Growth 300 (2007) 45.

2. K. Wafers, C. Bell, Oxides and hydroxides of aluminum, Alcoa Technical Paper no. 19, Alcoa Research Laboratories.

3. J. Li, M. Nakamyra, T. Shirai, K. Matsumary, C. Ishizaki, and K. Ishizaki, J.Am.Ceram. Soc., 89 [3] 937-943 (2006)

4. M.L. Panchula, J.Y. Ying, J. Am. Ceram. Soc. 86 (2003) 1114.

5. J. Edgar, L. Du, L. L. Nyakiti, J. Chaudhuri, J. Crystal Growth 310 (2008) 4002-4006

6. H.Fukuyama, S.Kusunoki, A.Hakomori, and K.Hiraga, J. Appl. Phys. 100, 024905 (2006)

7. Wataru Nakaoa, Hiroyuki Fukuyama, J. Crystal Growth 259 (2003) 4001-4006 302-308

8. NIST-JANAF Thermochemical Tables, 4th ed., M. W. Chase, Jr. Am. Chem. Soc., DC, 1998, Am. Inst. Phys., NY, 1998, the NIST, Gaithersburg, MD 1998.

9. L. Du and J.H. Edgar, Mater. Res. Soc. Symp. Proc. 955 I11-05 (2007). 